\title{
The management of prehypertension in young adults
}

\author{
Ma Jun, MD, Xiang Yali, MD.
}

\begin{abstract}

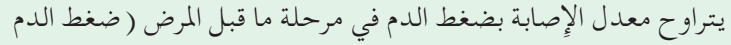

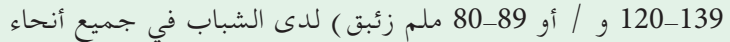

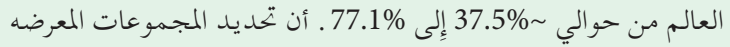

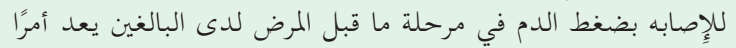

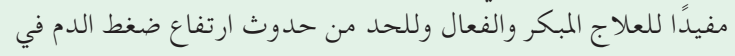

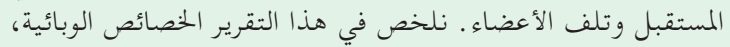

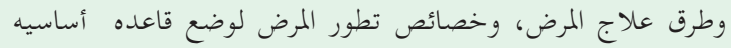

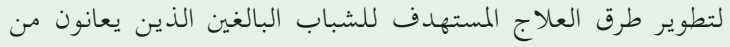

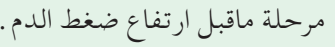

The incidence of prehypertension (blood pressure 120$139 \mathrm{and} /$ or $80-89 \mathrm{~mm} \mathrm{Hg}$ ) in young adults worldwide ranges from $-37.5 \%$ to $77.1 \%$. Identifying high-risk groups of prehypertension in young adults is helpful for early and effective interventions and treatments to reduce the occurrence of future hypertension and organ damage. This review summarized the epidemiological characteristics, disease intervention measures, and disease progression characteristics of prehypertension to provide a basis for the development of targeted intervention measures for young adults with prehypertension.

Keywords: pre-hypertension, young adults, blood pressure

Saudi Med J 2020; Vol. 41 (3): 223-231 doi: 10.15537/smj.2020.3.24998

From the Xiangya Nursing School (Jun), Central South University, Changsha and from the Health Management Center (Yali), The Fifth Affiliated Hospital of Sun Yat-sen University, Zhuhai, China.

Address correspondence and reprint request to: Ms. Xiang Yali, Health Management Center, The Fifth Affiliated Hospital of Sun Yat-Sen University, Zhuhai, China. E-mail: adaia0521@126.com ORCID ID: https://orcid.org/0000-0001-9862-2868
G pidemiological data shows that the incidence of prehypertension (HN) (blood pressure 120$139 / 80-89 \mathrm{~mm} \mathrm{Hg}$ ) ranges from $-37.5 \%$ to $77.1 \%$ in adults under 44 years old, ${ }^{1-3}$ especially in those with high uric acid levels, ${ }^{4}$ obesity, ${ }^{5}$ and impaired baseline blood sugar. ${ }^{6}$ Untreated prehypertensive individuals are thought more probably to developing $\mathrm{HN}, 7,8$ coronary heart disorder $(\mathrm{CHD})^{9-11}$ and renal disorder. ${ }^{12,13}$ The rates of diagnosis are consistently low in young adults (15-44 years old) ${ }^{14,15}$ which greatly increases the difficulty in the development and implementation of intervention strategies for $\mathrm{HN}$ and may lead to rapid onset of uncontrolled diseases in old age. In addition, young adults are unique and have different lifestyle practices, comorbid conditions, and disease characteristics.

To reduce the burden of CHD and end-stage renal failure (ESRF), it is necessary to summarize sufficient studies to provide convincing evidence for formulating interventions for prehypertensive youth. Some reviews analyzed the pathogenesis and intervention strategies for patients with $\mathrm{HN}$, but whether these strategies are applicable to young adults is still uncertain. Therefore, it is vital to know the risk factors and intervention measures for $\mathrm{HN}$ in young adults.

Epidemiology. Domestic epidemiological status. Prehypertension is widely distributed around the world and has become one of the most important diseases threatening human health, especially young adults. Prehypertension may be affected by different social and demographic factors, such as altitude, lifestyle, and ethnic group. Prehypertension is widespread among young Chinese adults, except for the Miao, Tibetan and Tujia ethnic groups. A study that explored the incidence of $\mathrm{HN}$ in different parts of China showed that the rate of $\mathrm{HN}$ is up to $48 \%$ in Northeast China ( $47.7 \%$ in men and $33.6 \%$ in women), ${ }^{1}$ which may be associated with cold weather and high-salt diets. However, many studies in recent years have suggested that the prevalence rate of $\mathrm{HN}$ is almost as high in Guangdong Province in South China, despite low-sodium diets. ${ }^{16}$ Prehypertension is also common in the She minority (35.9\%) in the hilly region of Fujian Province ${ }^{17}$ and the mountainous regions in Chongqing and the central plain (55.17\%). ${ }^{18}$ 
Prehypertensive morbidity is $63.2 \%$ in males and $47.2 \%$ in females ${ }^{19}$ and show a significant upward trend in both gender. ${ }^{20,21}$

Overseas epidemiological status. Outside of China, $\mathrm{HN}$ is widespread in one-quarter of Indian adults who aged $18-40$ years. ${ }^{22}$ Additionally, studies showed that the prehypertensive rate was 19\% among college students in Southeast $\mathrm{Asia}^{23}$ and $44.9 \%$ among young adults in Arab countries. ${ }^{24}$ Prehypertension used to be rare in African populations, but it is now one of the most common cardiovascular disease (CVD) and accounts for almost $40 \%$ of all diseases in Africa. ${ }^{25}$ A study with a large sample size suggested that the incidence of $\mathrm{HN}$ ranges from $37.5 \%$ to $42.5 \%$ in different regions and countries in Africa. ${ }^{26}$ Data on HN in the United States are limited, but available studies had suggested that the rates of $\mathrm{HN}$ decreased slightly from $81.5 \%$ in 1999 to $77.7 \%$ in $2012 .{ }^{27}$ In addition to areal variation, many social and demographic characteristics are significantly correlated with HN. For example, the incidence of $\mathrm{HN}$ was reported to be $55.3 \%$ in American football players $^{28}$ and $42.9 \%$ in police constables in a district of India, ${ }^{22}$ both of which are higher than that in the general young population. Prehypertensive morbidity is also significantly increased in young adults who have low incomes, low social status, ${ }^{29-31}$ and a family history of $\mathrm{HN} .^{32}$

Risk factors for prehypertension. Obesity. The possible association between overweight and/or obesity and $\mathrm{HN}$ in young adults has been confirmed in several studies. A survey showed that body mass index (BMI) was $22.5 \pm 3.2 \mathrm{~cm}$, waist circumference (WC) was $80.5 \pm 8.5 \mathrm{~cm}$ and hip circumference (HC) was $94.0 \pm 7.9 \mathrm{~cm}$ in prehypertensive young adults; BMI was $21.6 \pm 3.2 \mathrm{~cm}$, WC was $76.3 \pm 7.8 \mathrm{~cm}$, and $\mathrm{HC}$ was $91.3 \pm 7.8 \mathrm{~cm}$ in the general young population. And $\mathrm{HN}$ was more likely to occur in populations with central obesity (odds ratio $(\mathrm{OR})=1.9,95 \%$ confidence interval $(\mathrm{CI})=0.8-4.7){ }^{33} \mathrm{~A}$ cross-sectional study of 4649 college students in Southeast Asia showed that obesity increased the probability of $\mathrm{HN}(\mathrm{OR}=2.28$, 95\% $\mathrm{CI}=1.84-2.82, p<0.001)$ and that underweight was a protective factor. ${ }^{23}$ In addition, compared with BMI and waist-to-height ratio (WtHR), WC had a

Disclosure. Authors have no conflict of interests, and the work was not supported or funded by any drug company. higher predictive value for $\mathrm{HN}$ (95\% CI: 0.623-0.637, $p<0.0001)$, especially in males, ${ }^{34}$ and the synergistic effect of WC and BMI was superior to a single index in identifying hypertension. The risk of $\mathrm{HN}$ increased in both gender among individuals who had the same WC with increasing BMI. ${ }^{20}$ Being overweight has also been reported to increase the effect of ambient air pollution on HN. ${ }^{35}$ However, the effect of neck circumference as an independent predictor of $\mathrm{HN}$ was not clear $(\mathrm{OR}=1.102,95 \% \mathrm{CI}=1.007-1.201, p=0.049),{ }^{36}$ and it may be necessary to conduct a comparative study in a more representative group to elucidate the effect of this factor.

Pathological factors. Hyperuricemia is often reported to be independently associated with $\mathrm{HN} .{ }^{37} \mathrm{~A}$ multiple linear regression model in a substudy $(n=60)$ demonstrated that only uric acid was a decisive factor in blood pressure, especially in males. ${ }^{38}$ After standardizing the population by excluding people who were taking antihypertensive drugs, we found that people with high uric acid were more likely to present with $\mathrm{HN}$ $(\mathrm{OR}=1.50,95 \% \mathrm{CI}: 1.02-2.19) .{ }^{39}$ The role of age in the relationship among insulin resistance, abnormal glucose tolerance, and $\mathrm{HN}$ is currently unclear. A study showed that impaired baseline fasting glucose (OR: 1.70, 95\% CI: 1.07-2.69) was the strongest significant predictor of $\mathrm{HN} ;{ }^{40}$ however, in another study, researchers found that the number of patients with $\mathrm{HN}$ was almost equal to those with normotension in the <52-year-old age group with insulin resistance, which may indicate that insulin resistance cannot be used as an independent predictor of $\mathrm{HN}$ in young adults. ${ }^{41}$ Therefore, the issues of whether there is an interaction between abnormal glucose tolerance and insulin resistance and whether it has a direct influence on $\mathrm{HN}$ progression in young adults deserve further discussion. Few studies have reported a link between immune factors and $\mathrm{HN}$; one available study demonstrated that various inflammatory mediators, such as IgG, were involved in the nosogeny of $\mathrm{HN}$ through the mediation of anti-inflammatory and/ or proinflammatory pathways ${ }^{42}$ in Chinese, Croatian, and Scottish populations.

Table 1 summarize the risk factors for prehypertension in young adults.

Unhealthy lifestyle. Elevated blood pressure has been shown to be related to some of unique lifestyles of young adults. A study developed to determine the effect of hikikomori (young adults who stay at home in long-term seclusion) on physical health showed that the SF-36 scores of this group were high, but the rates of 
Table 1 - Summary of risk factors for prehypertension $(\mathrm{HN})$ in young adults.

\begin{tabular}{|c|c|c|}
\hline Variable & Risk factors & Controversy \\
\hline Obesity & Waist circumference, ${ }^{33}$ a combination of WC and BMI, abdominal obesity ${ }^{34}$ & Neck circumference ${ }^{36}$ \\
\hline Pathological factors & Hyperuricemia, ${ }^{37,39}$ impaired baseline fasting glucose, ${ }^{40}$ inflammatory mediators ${ }^{42}$ & $\begin{array}{l}\text { An interaction between abnormal } \\
\text { glucose tolerance and insulin resistance }{ }^{41}\end{array}$ \\
\hline Lifestyle & $\begin{array}{r}\text { Hikikomori, }{ }^{43} \text { sleep less than } 6 \text { hours, }{ }^{44} \text { decreased activity, }{ }^{29} \text { tobacco use and heavy } \\
\text { alcohol consumption }{ }^{23}\end{array}$ & \\
\hline Diet & High in salt and fat, ${ }^{45}$ soft drinks, chocolate or candies 1-6 times a week ${ }^{23}$ & \\
\hline $\begin{array}{l}\text { Social and } \\
\text { psychological factors }\end{array}$ & $\begin{array}{l}\text { Low life satisfaction,low social support and depressive symptoms, }{ }^{23} \text { prenatal life } \\
\text { stress events, }{ }^{46} \text { the wealth gap,Lower education and a history of marital status }{ }^{31}\end{array}$ & \\
\hline Other factors & Wrist fracture,spina bifida, ${ }^{47}$ a serum FT4 level increase of $1 \mathrm{ng} / \mathrm{dl}^{49}$ & $\begin{array}{c}\text { A significant association between } \\
\text { periodontal disease and hypertension } \\
\text { instead of } \mathrm{HN}^{48}\end{array}$ \\
\hline
\end{tabular}

$\mathrm{HN}$ remained as high as $31.7 \%$ and gradually increased in accordance with the concealment time, ${ }^{42}$ indicating that the lifestyle of "hikikomori" may be a related factor for obesity, cardiovascular disorders, and other chronic diseases among young adults. In addition, females aged 35-44 who slept less than 6 hours had an increased risk of $\mathrm{HN}(\mathrm{OR}=1.769,95 \% \mathrm{CI}: 1.058-2.958) .{ }^{44}$ Decreased activity, ${ }^{44}$ tobacco use $(\mathrm{OR}=1.65, p<0.01)$ and alcohol use at least monthly $(\mathrm{OR}=1.96,95 \% \mathrm{CI}=1.32-2.54$, $p<0.001)^{23}$ can also increase the risk of $\mathrm{HN}$ in young adults.

Unhealthy diet. Unhealthy diets, such as those high in salt and fat, have been identified as contributing factors to $\mathrm{HN}$ and hypertension in young adults. The average blood pressure of young adults who ate a high-salt diet was $130.40 \pm 7.20 / 86.10 \pm 4.05 \mathrm{mmHg}$, compared to $127.30 \pm 6.56 / 85.20 \pm 5.00 \mathrm{mmHg}$ in prehypertensive young adults who ate a normal diet. ${ }^{45}$ People who consumed more soft drinks $(\mathrm{OR}=1.56$, $p<0.001)$ and chocolates or candies 1-6 times a week $(\mathrm{OR}=0.73, p<0.01)$ were more likely to suffer from $\mathrm{HN} .{ }^{23}$ The relationship between other dietary factors and $\mathrm{HN}$ also deserves further investigation.

Social and psychological factors. In addition to physical changes, some psychological characteristics, such as low life satisfaction, low social support and depressive symptoms, have an impact on prehypertensive young adults. ${ }^{46}$ Prenatal life stress events can affect the blood pressure of young adults (systolic blood pressure [SBP]: $\mathrm{OR}=-0.66, p=0.013$ and diastolic blood pressure $[\mathrm{DBP}]: \mathrm{OR}=-0.40, p=0.047) .{ }^{23} \mathrm{In}$ addition, the wealth gap also played an important role in predicting the incidence of $\mathrm{HN}$, and the available evidence showed that the rate of $\mathrm{HN}$ in rural areas was dramatically high in both the poorest $(84.6 \%)$ and richest groups $(28.1 \%){ }^{31}$ Lower education levels and marriage status were also related to the incidence of $\mathrm{HN}$ among inhabitants in Chongqing, China. ${ }^{18}$

Other factors. Prehypertension is one of the most common complications of hip fracture, and a positive relationship between wrist fracture and $\mathrm{HN}$ remains significant $(\mathrm{OR}=1.48,95 \% \mathrm{CI}=1.10-1.99) .{ }^{47}$ However, whether other types of fracture are potential risk factors for $\mathrm{HN}$ is unclear. Young adults with spina bifida were more likely to suffer from HN compared with general individuals in the USA. ${ }^{47}$ Although some studies reported positive correlations between periodontal disorders and $\mathrm{HN}$, Kawabata found a significant relation between periodontal disorders and hypertension instead of $\mathrm{HN}$ after conducting a more rigorous prospective cohort study (OR: $0.93, p=0.82) .{ }^{48}$ Additionally, a serum free thyroxine (FT4) level increase of $1 \mathrm{ng} / \mathrm{dl}$ was related to a $40 \%$ increase in risk of $\mathrm{HN}$ $(\mathrm{OR}=1.40,95 \% \mathrm{CI}=1.02-1.90){ }^{49}$

Prehypertensive intervention strategies. The 13th European Society of Hypertension in Milan in 2003 mentioned that patients should make active lifestyle changes, such as smoking cessation, weight control, salt restriction, and physical activity enhancement. Additionally, medication should be considered for patients who have more than 3 risk factors, and those patients who have diabetes mellitus and target organ damage should start drug treatment immediately if simple lifestyle changes cannot decrease blood pressure to below 130/80 $\mathrm{mm} \mathrm{Hg}$.

Prehypertension screening. Prehypertensive young adults may have milder clinical symptoms, making HN 
more difficult to be diagnosed in young patients than in elderly patients. Therefore, in addition to effective interventions for diagnosed individuals, effective disease screening is necessary to improve prevention and awareness in potential HN patients. Both BMI and $\mathrm{WC}$ can be used to estimate the risk of $\mathrm{HN},{ }^{50}$ and screening trials that focus attention on blood pressure and BMI can also help identify the related factors of cardiovascular disorders. ${ }^{14}$ Additionally, dynamic blood pressure monitoring, ${ }^{51}$ especially DBP monitoring, ${ }^{15}$ is conducive to the early recognition and administration of occult hypertension in young adults with HN.

Dietary intervention. Recent studies have suggested that there are some protective factors for $\mathrm{HN}$, such as being a woman and highly educated, having a high household income and a healthy diet. ${ }^{15}$ Therefore, dietary interventions seem to be wise methods for preventing $\mathrm{HN}$ in young adults with high uric acid and those with smoking and alcohol consumption habits. ${ }^{38}$ Foods with high salt and fat content have been recognized as dangerous risk factors for the development of $\mathrm{HN}$. One study showed that the mean SBP was lower in young adults who consumed a low-salt diet than in young adults who consumed a high-salt diet (daytime $0.7 \pm 5.8 \mathrm{~mm} \mathrm{Hg}, p=0.008$; night time $1.3 \pm 6.1 \mathrm{~mm} \mathrm{Hg}, p<0.0001) .{ }^{52}$ Juraschek found that moderate sodium intake (OR: $-0.35, p=0.04)$ and high sodium intake (OR: $-0.33, p=0.003$ ) significantly reduced uric acid in all subjects compared to low sodium intake. ${ }^{53}$ Functional foods are becoming popular with health-conscious citizens, as they offer a promising and effective nutritional strategy; for example, dietary polyphenols have shown potential benefits in the management of $\mathrm{HN}$ through the improvement and restoration of endothelial dysfunction and a decline in blood pressure. ${ }^{54}$ In addition, a number of vegetables have high levels of nitrates, which can be reduced to nitrites by oral bacteria, undergo further reduction to a kind of endogenous vasoprotective factor, nitric oxide (NO), and eventually indirectly achieve the goal of controlling blood pressure. For instance, a decline in SBP $(p<0.01)$ and DBP $(p<0.001)$ were closely associated with daily intake of beetroot juice, with water intake as the control, in a dose-dependent manner in young adults. ${ }^{55}$

Lifestyle intervention. Comprehensive lifestyle changes, such as maintaining good sleep habits and increasing physical activity appropriately, are imperative because they can reduce the incidence of HN. ${ }^{1}$ Aerobic exercise is regarded as the main form of exercise for young adults with HN because it has direct and continuous benefits on blood pressure and could decrease the blood pressure of prehypertensive patients by $5-7 \mathrm{mmHg}$ on average. ${ }^{56} \mathrm{~A}$ meta-analysis showed that exercise reduced SBP by $4.40 \mathrm{mmHg}$ and DBP by $4.17 \mathrm{~mm} \mathrm{Hg}$ in 3 months. ${ }^{57}$ Furthermore, Sales et $\mathrm{al}^{58}$ discovered that SBP in young women dropped from $128.2 \pm 6.6 \mathrm{~mm}$ $\mathrm{Hg}$ to $118.0 \pm 8.2 \mathrm{~mm} \mathrm{Hg}(p<0.05)$ after a 12-week diet and exercise management program. Beck et $\mathrm{al}^{59}$ also found that both resting SBP and DBP were similarly decreased in the HN groups after 8 weeks of resistance or endurance training. In addition, the difference in the changes in both SBP $(p<0.01)$ and DBP $(p<0.01)$ after an 8-week intervention between the Qigong group and the matched group were statistically significant. ${ }^{60}$

Table 2 summarize the interventions for prehypertension in young adults.

Drug therapy. Drug treatment may be a costeffective method to help stem the epidemic of $\mathrm{HN}$ in young adults who are currently free of CVD and may eventually reduce complications of $\mathrm{HN}$. Julius et $\mathrm{al}^{61}$ and Luders et $\mathrm{al}^{62}$ suggested that the candesartan and angiotensin-converting enzyme inhibitor ramipril can reduce the risk of HN. Bhagatwala et $\mathrm{al}^{63}$ found that there was a significant decline in peripheral SBP $(-7.06 \pm 2.25 \mathrm{~mm} \mathrm{Hg})$, peripheral

Table 2 - Summary of interventions for prehypertension in young adults.

\begin{tabular}{|c|c|c|}
\hline Variable & Intervention strategies & Deficiency \\
\hline Prehypertension screening & $\begin{array}{l}\text { Screening trials focusing on blood pressure and body } \\
\text { mass index, dynamic blood pressure monitoring }{ }^{13,51}\end{array}$ & \\
\hline Dietary intervention & $\begin{array}{l}\text { A low-salt diet, }{ }^{53} \text { moderate sodium intake and high } \\
\text { sodium intake, }{ }^{54} \text { dietary polyphenols, }{ }^{55} \text { beetroot juice }{ }^{56}\end{array}$ & $\begin{array}{c}\text { Lack of comparison between different types of food or } \\
\text { eating patterns }\end{array}$ \\
\hline Lifestyle intervention & $\begin{array}{c}\text { Aerobic exercise, }{ }^{57} \text { resistance or endurance training, }{ }^{59,60} \\
\text { Qigong }{ }^{61}\end{array}$ & $\begin{array}{l}\text { Current intervention strategies do not maintain long- } \\
\text { term benefit }\end{array}$ \\
\hline Drug therapy & $\begin{array}{l}\text { Amiloride monotherapy, }{ }^{62} \text { allopurinol, }{ }^{63} \text { acute dietary } \\
\text { supplementation of a single dose of grape seed extract }{ }^{64}\end{array}$ & $\begin{array}{l}\text { Lack of analysis of interactive effects between other } \\
\text { interventions and prescription medication }\end{array}$ \\
\hline
\end{tabular}


DBP $(-4.35 \pm 1.67 \mathrm{~mm} \mathrm{Hg})$, central SBP $(-7.68 \pm 2.56$ $\mathrm{mm} \mathrm{Hg})$, and central DBP $(-4.49 \pm 1.78 \mathrm{~mm} \mathrm{Hg})$ after 4 weeks of amiloride monotherapy. Fuchs et $\mathrm{al}^{64}$ conducted a series of studies to explore the effectiveness of low-dose diuretic in adults with $\mathrm{HN}$, and in 2016, they found that the combination of low-dose chlorthalidone and amiloride can effectively decrease the risk of hypertension and can benefient the left ventricular mass of patients, but their recent study indicated that a fixed association of chlorthalidone $12.5 \mathrm{mg}$ and amiloride $2.5 \mathrm{mg}$ didn't get most patients' blood pressure down to the ideal level. ${ }^{65}$ Allopurinol can reduce the serum uric acid level $(p<0.01)$ and prevent the rise of 24-hours ambulatory DBP and daytime SBP and DBP. ${ }^{66}$ Blood pressure can also be reduced in prehypertensive males by acute dietary supplementation of a single dose of grape seed extract. ${ }^{67}$

Disease progression of prehypertension in young adults. Circulatory system damage. Prehypertension is closely related to CVD, and meta-analysis showed that HN dramatically increased the risk of CVD (relative risk (RR) 1.28, 95\% CI 1.16-1.40), CHD $(p<0.01)$ and stroke mortality $(p<0.01)$, and the death of patients with CVD was largely driven by high-range $\mathrm{HN}$ (130-139 and/or $85-89 \mathrm{mmHg}),{ }^{68}$ but even slightly elevated BP within the normal range is associated with cardiac end-organ damage. ${ }^{69}$ Ennis et $\mathrm{al}^{70}$ demonstrated that left ventricular structural damage (left ventricular mass in $\mathrm{HN}(31.26 \pm 0.73 \mathrm{~g} / \mathrm{m}(2.7), p<0.01)$, diastolic function (the e'/a' ratio was $2.03 \pm 0.06$ in $\mathrm{HN}$, which is lower than optimal, $p<0.03$ ) and vascular dilation (aortic distensibility in $\mathrm{HN}(1.41 \pm 0.05 \mathrm{~mm} \mathrm{Hg} / \mathrm{cm}$ $(3) / \mathrm{m}(2), p<0.01)$ were impaired in prehypertensive youths, especially those with high-range $\mathrm{HN} .{ }^{70}$ In Markus' study, the HN group displayed more obvious aging-related increases of left ventricular wall thickness $(p<0.001)$ and left ventricular mass $(p=0.006)$, and $\mathrm{HN}$ was related to a raised incidence of left ventricular concentric remodeling (adjusted OR 10.7, 95\% CI 2.82-40.4) and left ventricular hypertrophy (adjusted OR 5.33, 95\% CI 1.58-17.9). ${ }^{81}$ Kurioka et $\mathrm{al}^{72}$ also suggested that both high-range and low-range HN were independent risk factors for $\mathrm{CHD}$ even in population aged 24-34 years. $^{8}$ Thus, CVDs and cerebrovascular diseases, such as abdominal aortic aneurysms, ${ }^{72} \mathrm{CHD}$ $(\mathrm{RR}=1.43, \quad p<0.01),{ }^{10}$ intracranial arterial stenosis (ICAS) $(\mathrm{OR}=1.55,95 \% \mathrm{CI}=1.11-2.16, p=0.010)^{11}$ and stroke $(\mathrm{RR}=1.66,95 \% \mathrm{CI}=1.51-1.81)$, are associated with HN. ${ }^{73}$
It is common for $\mathrm{HN}$ to progress to hypertension, and the 50th decade of life would be a critical period for this progression to occur. ${ }^{33} \mathrm{~A}$ study in Japan showed that the relationship between baseline blood pressure and progressive blood pressure was stronger in the group aged 20-34 years than in the older age groups, especially in men. ${ }^{33}$ Additionally, young adults with $\mathrm{HN}$ had a lower ankle-brachial index (ABI <0.90; $\mathrm{OR}=3.288,95 \% \mathrm{CI}=1.5-7.0, p=0.0023$ ) and a higher incidence of peripheral artery disorders compared to the general population. ${ }^{74}$

Endocrine system damage. The evidence for a link between $\mathrm{HN}$ and diabetes in young adults is limited, but the available evidence shows that baseline hypertension is a standalone predictive factor of incident diabetes mellitus $(\mathrm{OR}=3.33, p<0.01)$. The serum retinol-binding protein 4 level was higher and independently related to SBP and DBP in prehypertensive Chinese young adults. ${ }^{75}$ Moreover, recent evidence showed that an increase in serum aldosterone was correlated with $\mathrm{HN}$ in the general population. ${ }^{76}$

Urinary system damage. Recent evidence showed that the prevalence of microalbuminuria was $6.8 \%$ in $\mathrm{HN}$ group and $3.6 \%$ in an optimal blood pressure group $(p<0.001) .^{77}$ A study suggested that $\mathrm{HN}$ had an all-important relationship with microalbuminuria $(\mathrm{OR}=2.50, p<0.05)$ in the diabetes subgroup compared with the ideal blood pressure group, ${ }^{78}$ indicating that there was an interaction between $\mathrm{HN}$ and diabetes mellitus, both of which may be predictors of slightly elevated albumin levels in urine. However, in another study, HN was more likely to be associated with slightly increased urinary albumin levels $(\mathrm{OR}=1.83$, $p<0.05)$ after eliminating individuals with diabetes or hyperuricemia or those who used hypotensive drugs, ${ }^{39}$ indicating that $\mathrm{HN}$ may be an independent predictor of microalbuminuria.

Subjects in the HN group had a mean B-type natriuretic peptide (BNP) level of $98(72) \mathrm{pg} / \mathrm{mL}$ compared with $43.6(20) \mathrm{pg} / \mathrm{mL}$ found among subjects in the normotension group $(p<0.001) .{ }^{79}$ Bo found that the adjusted OR was 3.4 in the HN group and 1.6 in the control group in an attribution analysis of renal function injury; ${ }^{80}$ both of these results suggest that persistent $\mathrm{HN}$ may be a standalone predictive factor of renal insufficiency. In addition to simple renal impairment, significantly higher numbers of simple renal cysts (SRCs) have been reported in young adults with $\mathrm{HN}$ and hypertension than in 
those with normotension. ${ }^{13}$ Similarly, $\mathrm{HN}$ increased the risk of chronic kidney disease $(\mathrm{CKD})(\mathrm{RR}=1.28$, $p<0.000) .{ }^{81}$ The accumulated morbidity of CKD was higher in individuals with HN than in those in the general population $(2.10 \%$ versus $1.46 \%, p<0.01){ }^{82}$ In addition, a survey of 2.19 million young adults in the USA also indicated that prehypertensive patients had a $32 \%$ chance of advanced ESRF compared with individuals in the general population. ${ }^{12}$

Effects on pregnant women. Mild elevation of blood pressure during gestation can lead to high blood pressure or other diseases later in life. Studies have shown that after delivering a live infant, women with higher DBP levels (from $76.2+/-6.7$ to $81.8+/-4.8 \mathrm{~mm} \mathrm{Hg}$ ) are more likely to suffer postpartum metabolic syndrome $(\mathrm{OR}=6.55, P<0.01)$ than women with lower DBP levels. ${ }^{83} \mathrm{HN}$ in early pregnancy also had significant effects on total preeclampsia, early preeclampsia and severe preeclampsia (all $p<0.05) .{ }^{84}$ In addition to the effect on pregnant women, $\mathrm{HN}$ is also related to both threatened premature labor and stillbirths. ${ }^{85}$ Formulation of specific strategies for prehypertensive women in the child-bearing period has become a focus of research.

Other progressions in prehypertension. Autonomic dysfunction is both a cause and an effect of $\mathrm{HN}$. Moinuddin found that there were 3 main changes in autonomic function in prehypertensive young adult males. First, sympathetic activity showed a significant increase among prehypertensive individuals characterized by a low increase in DBP $(\mathrm{mmHg})$ in response to a hand-grip test (HGT) $(11.27+/-3.76$ $\mathrm{mm} \mathrm{Hg}$ vs $23.95 \pm 6.29 \mathrm{~mm} \mathrm{Hg},[p<0.05])$. Second, the sympathovagal balance showed prominent sympathetic activity $(2.85 \pm 1.78$ versus $1.75 \pm 0.98 ; p<0.01)$. Finally, parasympathetic activity was dramatically decreased. ${ }^{86}$

In conclusion, $\mathrm{HN}$ continues to progress in young adults, but there are few rigorous randomized controlled trials to test the effectiveness, particularly the long-term utility, of exercise and lifestyle improvements. Further and practical research on young adults to construct a practical intervention model for prehypertension will be the focus of future research and will be significantly cost effective.

\section{References}

1. Meng XJ, Dong GH, Wang D, Liu MM, Liu YQ, Zhao Y, et al. Epidemiology of prehypertension and associated risk factors in urban adults from 33 communities in China. the CHPSNE study. Circ J 2012; 76: 900-906.
2. Paquissi FC, Manuel V, Manuel A, Mateus GL, David B, Beu $\mathrm{G}$, et al. Prevalence of cardiovascular risk factors among workers at a private tertiary center in Angola. Vasc Health Risk Manag 2016; 12: 497-503.

3. Afrifa-Anane E, Agyemang C, Codjoe SN, Ogedegbe G, De-Graft AA. The association of physical activity, body mass index and the blood pressure levels among urban poor youth in Accra, Ghana. Bmc Public Health 2015; 15: 269.

4. Peng H, Ding J, Peng Y, Zhang Q, Xu Y, Chao X, et al. Hyperuricemia and microalbuminuria are separately and independently associated with prehypertension among Chinese Han women. Metab Syndr Relat Disord 2012; 10: 202-208.

5. Isezuo SA, Sabir AA, Ohwovorilole AE, Fasanmade OA. Prevalence, associated factors and relationship between prehypertension and hypertension: a study of two ethnic African populations in Northern Nigeria. J Hum Hypertens 2011; 25: 224-230.

6. Donahue RP, Stranges S, Rafalson L, Dmochowski J, Dorn J, Trevisan M. Risk factors for prehypertension in the community: a prospective analysis from the Western New York Health Study. Nutr Metab Cardiovasc Dis 2014; 24: 162-167.

7. Moreira LB, Fuchs SC, Wiehe M, Gus M, Moraes RS, Fuchs FD. Incidence of hypertension in Porto Alegre, Brazil: a population-based study. J Hum Hypertens 2008; 22: 48-50.

8. Kurioka S, Horie S, Inoue A, Mafune K, Tsuda Y, Otsuji Y. Risk of progression to hypertension in nonhypertensive Japanese workers aged 20-64 years. J Hypertens 2014; 32: 236-244.

9. Selassie A, Wagner CS, Laken ML, Ferguson ML, Ferdinand $\mathrm{KC}$, Egan BM. Progression is accelerated from prehypertension to hypertension in blacks. Hypertension 2011; 58: 579-587.

10. Huang Y, Cai X, Liu C, Zhu D, Hua J, Hu Y, et al. Prehypertension and the risk of coronary heart disease in Asian and Western populations: a meta-analysis. J Am Heart Assoc 2015; 4: (2).

11. Wang D, Zhou Y, Guo Y, Wang C, Wang A, Jin Z, et al. Arterial pre-hypertension and hypertension in intracranial versus extracranial cerebrovascular stenosis. Eur J Neurol 2015; 22: 533-539.

12. Leiba A, Twig G, Vivante A, Skorecki K, Golan E, Derazne E, et al. Prehypertension among 2.19 million adolescents and future risk for end-stage renal disease. J Hypertens 2017; 35: 1290-1296.

13. Karoli R, Bhat S, Fatima J, Shukla V, Khanduri S, Rehman M, et al. Simple Renal Cysts: Can They be Overlooked? J Assoc Physicians India 2016; 64: 14-17.

14. Karaduman M, Aparci M, Unlu M, Ozturk C, Balta S, Celik $\mathrm{T}$. Role of screening tests in the detection and management of blood pressure abnormalities among young population. Angiology 2017; 68: 441-446.

15. Kanegae H, Oikawa T, Okawara Y, Hoshide S, Kario K. Which blood pressure measurement, systolic or diastolic, better predicts future hypertension in normotensive young adults? $J$ Clin Hypertens (Greenwich) 2017; 19: 603-610.

16. Huang Y, Qiu W, Liu C, Zhu D, Hua J, Cai X, et al. Prevalence and risk factors associated with prehypertension in Shunde District, southern China. BMJ Open 2014; 4: e6551.

17. Lin Y, Lai X, Chen G, Xu Y, Huang B, Chen Z, et al. Prevalence and risk factors associated with prehypertension and hypertension in the Chinese She population. Kidney Blood Press Res 2012; 35: 305-313. 
18. Zhang R, Deng R, Shen P, Fan M, Leng B, Zhou Y, et al. Prehypertension and socioeconomic status: A cross-sectional study in Chongqing, China. Clin Exp Hypertens 2017; 39: 774-780.

19. Chen C, Yuan Z. Prevalence and risk factors for prehypertension and hypertension among adults in Central China from 2000-2011. Clin Exp Hypertens 2018; 40: 734-743.

20. Hu L, Huang X, You C, Li J, Hong K, Li P, et al. Prevalence and risk factors of prehypertension and hypertension in Southern China. Plos One 2017; 12: e170238.

21. Xu T, Liu J, Zhu G, Liu J, Han S. Prevalence of prehypertension and associated risk factors among Chinese adults from a large-scale multi-ethnic population survey. BMC Public Health 2016; 16: 775 .

22. Mallik D, Mukhopadhyay DK, Kumar P, Sinhababu A. Hypertension, Prehypertension and Normotension among Police Personnel in a District of West Bengal, India. J Assoc Physicians India 2014; 62: 12-16.

23. Peltzer K, Pengpid S, Sychareun V, Ferrer A, Low WY, Huu TN, et al. Prehypertension and psychosocial risk factors among university students in ASEAN countries. BMC Cardiovasc Disord 2017; 17: 230.

24. Aldiab A, Shubair MM, Al-Zahrani JM, Aldossari KK, Al-Ghamdi S, Househ M, et al. Prevalence of hypertension and prehypertension and its associated cardioembolic risk factors; a population based cross-sectional study in Alkharj, Saudi Arabia. BMC Public Health 2018; 18: 1327.

25. Mengistu MD. Pattern of blood pressure distribution and prevalence of hypertension and prehypertension among adults in Northern Ethiopia: disclosing the hidden burden. BMC Cardiovasc Disord 2014; 14: 33.

26. Kayima J, Nankabirwa J, Sinabulya I, Nakibuuka J, Zhu X, Rahman $\mathrm{M}$, et al. Determinants of hypertension in a young adult Ugandan population in epidemiological transition-the MEPI-CVD survey. BMC Public Health 2015; 15: 830.

27. Booth JR, Li J, Zhang L, Chen L, Muntner P, Egan B. Trends in Prehypertension and Hypertension Risk Factors in US Adults: 1999-2012. Hypertension 2017; 70: 275-284.

28. Tucker AM, Lincoln AE, Vogel RA, Black HR, Dunn RE, Wilson PW, et al. Lack of blood pressure difference by race in professional American football players. J Am Soc Hypertens 2015; 9: 370-374.

29. Zhang H, Deng M, Xu H, Wang H, Song F, Bao C, et al. Pre- and undiagnosed-hypertension in urban Chinese adults: a population-based cross-sectional study. J Hum Hypertens 2017; 31: 263-269.

30. Parthaje PM, Unnikrishnan B, Thankappan KR, Thapar R, Fatt QK, Oldenburg B. Prevalence and Correlates of Prehypertension Among Adults in Urban South India. Asia Pac J Public Health 2016; 28 (1 Suppl): 93S-101S.

31. Biswas T, Islam MS, Linton N, Rawal LB. Socio-economic inequality of chronic non-communicable diseases in Bangladesh. PLOS One 2016; 11: e167140.

32. Shen Y, Chang C, Zhang J, Jiang Y, Ni B, Wang Y. Prevalence and risk factors associated with hypertension and prehypertension in a working population at high altitude in China: a crosssectional study. Environ Health Prev Med 2017; 22: 19.

33. Isezuo SA, Sabir AA, Ohwovorilole AE, Fasanmade OA. Prevalence, associated factors and relationship between prehypertension and hypertension: a study of two ethnic African populations in Northern Nigeria. J Hum Hypertens 2011; 25: 224-230
34. Ma M, Tan X, Zhu S. Prehypertension and its optimal indicator among adults in Hubei Province, Central China, 2013-2015. Clin Exp Hypertens 2017; 39: 532-538.

35. Yang BY, Qian ZM, Vaughn MG, Howard SW, Pemberton JP, Ma H, et al. Overweight modifies the association between long-term ambient air pollution and prehypertension in Chinese adults: the 33 Communities Chinese Health Study. Environ Health 2018; 17: 57.

36. Liang J, Wang Y, Dou L, Li H, Liu X, Qiu Q, et al. Neck circumference and prehypertension: the cardiometabolic risk in Chinese study. J Hypertens 2015; 33: 275-278.

37. Wu IH, Wu JS, Sun ZJ, Lu FH, Chang CS, Chang CJ, et al. Higher serum uric acid level increases risk of prehypertension in subjects with normal glucose tolerance, but not pre-diabetes and diabetes. J Hum Hypertens 2016; 30: 479-482.

38. Sidoti A, Nigrelli S, Rosati A, Bigazzi R, Caprioli R, Fanelli $\mathrm{R}$, et al. Body mass index, fat free mass, uric acid, and renal function as blood pressure levels determinants in young adults. Nephrology (Carlton) 2017; 22: 279-285.

39. Peng H, Ding J, Peng Y, Zhang Q, Xu Y, Chao X, et al. Hyperuricemia and microalbuminuria are separately and independently associated with prehypertension among Chinese Han women. Metab Syndr Relat Disord 2012; 10: 202-208.

40. Donahue RP, Stranges S, Rafalson L, Dmochowski J, Dorn J, Trevisan M. Risk factors for prehypertension in the community: a prospective analysis from the Western New York Health Study. Nutr Metab Cardiovasc Dis 2014; 24: 162-167.

41. Jung $\mathrm{CH}$, Jung $\mathrm{SH}$, Lee B, Rosenberg M, Reaven GM, Kim SH. Relationship among age, insulin resistance, and blood pressure. J Am Soc Hypertens 2017; 11: 359-365.

42. Wang Y, Klaric L, Yu X, Thaqi K, Dong J, Novokmet M, et al. The association between glycosylation of immunoglobulin $\mathrm{G}$ and hypertension: A multiple ethnic cross-sectional study. Medicine (Baltimore) 2016; 95: e3379.

43. Yuen J, Yan Y, Wong V, Tam W, So KW, Chien WT. A physical health profile of youths living with a "Hikikomori" lifestyle. Int J Environ Res Public Health 2018; 15: (2).

44. Sun XM, Yao S, Hu SJ, Liu ZY, Yang YJ, Yuan ZY, et al. Short sleep duration is associated with increased risk of prehypertension and hypertension in Chinese early middle-aged females. Sleep Breath 2016; 20: 1355-1362.

45. Pal GK, Adithan C, Dutta TK, Pal P, Nanda N, Syamsundara $\mathrm{KA}$, et al. Preference for salt contributes to sympathovagal imbalance in the genesis of prehypertension. Eur J Clin Nutr 2013; 67: 586-591.

46. Bhat SK, Beilin LJ, Robinson M, Burrows S, Mori TA. Contrasting effects of prenatal life stress on blood pressure and body mass index in young adults. J Hypertens 2015; 33: 711-719.

47. Stepanczuk BC, Dicianno BE, Webb TS. Young adults with spina bifida may have higher occurrence of prehypertension and hypertension. Am J Phys Med Rehabil 2014; 93: 200-206.

48. Kawabata Y, Ekuni D, Miyai H, Kataoka K, Yamane M, Mizutani S, et al. Relationship between prehypertension/ hypertension and periodontal disease: A prospective cohort study. Am J Hypertens 2016; 29: 388-396.

49. Abdi H, Gharibzadeh S, Tasdighi E, Amouzegar A, Mehran L, Tohidi M, et al. Associations between thyroid and blood pressure in euthyroid adults: A 9-year longitudinal study. Horm Metab Res 2018; 50: 236-241. 
50. Ononamadu CJ, Ezekwesili CN, Onyeukwu OF, Umeoguaju UF, Ezeigwe OC, Ihegboro GO. Comparative analysis of anthropometric indices of obesity as correlates and potential predictors of risk for hypertension and prehypertension in a population in Nigeria. Cardiovasc J Afr 2017; 28: 92-99.

51. Unsal S, Ozkara A, Albayrak T, Ozturk Y, Beysel S, Kucukler FK. Evaluation of prehypertension and masked hypertension rate among clinically normotensive patients. Clin Exp Hypertens. 2016; 38: 218-224.

52. Montasser ME, Douglas JA, Roy-Gagnon MH, Van Hout CV, Weir MR, Vogel R, et al. Determinants of blood pressure response to low-salt intake in a healthy adult population. J Clin Hypertens (Greenwich) 2011; 13: 795-800.

53. Juraschek SP, Gelber AC, Choi HK, Appel LJ, Miller ER. Effects of the Dietary Approaches to Stop Hypertension (DASH) Diet and Sodium Intake on Serum Uric Acid. Arthritis Rheumatol. 2016; 68: 3002-3009.

54. Davinelli S, Scapagnini G. Polyphenols: a Promising Nutritional Approach to Prevent or Reduce the Progression of Prehypertension. High Blood Press Cardiovasc Prev 2016; 23: 197-202.

55. Hobbs DA, Kaffa N, George TW, Methven L, Lovegrove JA. Blood pressure-lowering effects of beetroot juice and novel beetroot-enriched bread products in normotensive male subjects. Br J Nutr 2012; 108: 2066-2074.

56. Ash GI, Taylor BA, Thompson PD, MacDonald HV, Lamberti $\mathrm{L}$, Chen $\mathrm{MH}$, et al. The antihypertensive effects of aerobic versus isometric handgrip resistance exercise. J Hypertens 2017; 35: 291-299.

57. Williamson W, Foster C, Reid H, Kelly P, Lewandowski AJ, Boardman $\mathrm{H}$, et al. Will Exercise Advice Be Sufficient for Treatment of Young Adults With Prehypertension and Hypertension? A Systematic Review and Meta-Analysis. Hypertension 2016; 68: 78-87.

58. Sales AR, Silva BM, Neves FJ, Rocha NG, Medeiros RF, Castro RR, et al. Diet and exercise training reduce blood pressure and improve autonomic modulation in women with prehypertension. Eur J Appl Physiol 2012; 112: 3369-3378.

59. Beck DT, Martin JS, Casey DP, Braith RW. Exercise training improves endothelial function in resistance arteries of young prehypertensives. J Hum Hypertens 2014; 28: 303-309.

60. Park JE, Hong S, Lee M, Park T, Kang K, Jung H, et al. Randomized, controlled trial of qigong for treatment of prehypertension and mild essential hypertension. Altern Ther Health Med 2014; 20: 21-30.

61. Julius S, Nesbitt SD, Egan BM, Weber MA, Michelson EL, Kaciroti N, et al. Feasibility of treating prehypertension with an angiotensin-receptor blocker. $N$ Engl J Med 2006; 354: 1685-1697.

62. Luders S, Schrader J, Berger J, Unger T, Zidek W, Bohm M, et al. The PHARAO study: prevention of hypertension with the angiotensin-converting enzyme inhibitor ramipril in patients with high-normal blood pressure: a prospective, randomized, controlled prevention trial of the German Hypertension League. J Hypertens 2008; 26: 1487-1496.

63. Bhagatwala J, Harris RA, Parikh SJ, Zhu H, Huang Y, Kotak I, et al. Epithelial sodium channel inhibition by amiloride on blood pressure and cardiovascular disease risk in young prehypertensives. J Clin Hypertens (Greenwich) 2014; 16: 47-53.
64. Fuchs SC, Poli-de-Figueiredo CE, Figueiredo NJ, Scala LC, Whelton PK, Mosele F, et al. Effectiveness of Chlorthalidone Plus Amiloride for the Prevention of Hypertension: The PREVER-Prevention Randomized Clinical Trial. J Am Heart Assoc 2016; 5: (12).

65. Fuchs FD, Fuchs SC, Poli-de-Figueiredo CE, Figueiredo NJ, Scala L, Vilela-Martin JF, et al. Effectiveness of low-dose diuretics for blood pressure reduction to optimal values in prehypertension: a randomized clinical trial. J Hypertens 2018; 36: 933-938.

66. Perez-Pozo SE, Schold J, Nakagawa T, Sanchez-Lozada LG, Johnson RJ, Lillo JL. Excessive fructose intake induces the features of metabolic syndrome in healthy adult men: role of uric acid in the hypertensive response. Int J Obes (Lond) 2010; 34: 454-461.

67. Kim JK, Kim KA, Choi HM, Park SK, Stebbins CL. Grape Seed Extract Supplementation Attenuates the Blood Pressure Response to Exercise in Prehypertensive Men. J Med Food 2018; 21: 445-453.

68. Huang Y, Su L, Cai X, Mai W, Wang S, Hu Y, et al. Association of all-cause and cardiovascular mortality with prehypertension: a meta-analysis. Am Heart J 2014; 167: 160-168.

69. Santos AB, Gupta DK, Bello NA, Gori M, Claggett B, Fuchs FD, et al. Prehypertension is Associated With Abnormalities of Cardiac Structure and Function in the Atherosclerosis Risk in Communities Study. Am J Hypertens 2016; 29: 568-574.

70. Ennis IL, Pinilla OA, Escudero EM. [Early cardiovascular changes in young people with normal and normal-high blood pressure]. Hipertens Riesgo Vasc 2016; 33: 86-92.

71. Markus MR, Stritzke J, Lieb W, Mayer B, Luchner A, Doring A, et al. Implications of persistent prehypertension for ageingrelated changes in left ventricular geometry and function: the MONICA/KORA Augsburg study. J Hypertens 2008; 26 : 2040-2049.

72. Pannarale G, Moroni C, Acconcia MC, Pannitteri G, Truscelli $\mathrm{G}$, Valente L, et al. The natural history of prehypertension. A 20-year follow-up. Eur Rev Med Pharmacol Sci 2017; 21: 1329-1334.

73. Huang Y, Cai X, Li Y, Su L, Mai W, Wang S, et al. Prehypertension and the risk of stroke: a meta-analysis. Neurology 2014; 82: 1153-1161.

74. Rubio-Guerra AF, Garro-Almendaro AK, Lozano-Nuevo JJ, Arana-Pazos KC, Duran-Salgado MB, Morales-Lopez H. Prehypertension is associated with peripheral arterial disease and low ankle-brachial index. Indian Heart J 2018; 70: 502-505.

75. Zhang JX, Zhu GP, Zhang BL, Cheng YY. Elevated serum retinol-binding protein 4 levels are correlated with blood pressure in prehypertensive Chinese. J Hum Hypertens 2017; 31: 611-615.

76. Piaditis G, Markou A, Papanastasiou L, Androulakis II, Kaltsas G. Progress in aldosteronism: a review of the prevalence of primary aldosteronism in pre-hypertension and hypertension. Eur J Endocrinol 2015; 172: R191-R203.

77. Tsimihodimos V, Gonzalez-Villalpando C, Meigs JB, Ferrannini E. Hypertension and Diabetes Mellitus: Coprediction and Time Trajectories. Hypertension 2018; 71: 422-428.

78. Wang Q, Huang J, Sun Y, Zhang W, Gao Y, Yao W, et al. Association of microalbuminuria with diabetes is stronger in people with prehypertension compared to those with ideal blood pressure. Nephrology (Carlton) 2018; 23: 690-696. 
79. Yi H, Zhang WZ, Zhang H, Chen YH, Zhou MC. Subclinical target organ damage in normotensive and prehypertensive patients. Minerva Cardioangiol 2017; 65: 16-23.

80. Bo S, Gruden G, Charbonnier E, Martorana M, Gambino R, Cassader M, et al. High-normal blood pressure and impaired renal function. A prospective study in a population-based cohort. Minerva Med 2014; 105: 211-219.

81. Li Y, Xia P, Xu L, Wang Y, Chen L. A Meta-Analysis on Prehypertension and Chronic Kidney Disease. PLOS One 2016; 11: e156575.

82. Xue H, Wang J, Hou J, Li J, Gao J, Chen S, et al. Prehypertension and chronic kidney disease in chinese population: Four-year follow-up study. PLOS One 2015; 10: e144438.
83. Lei Q, Zhou X, Zhou YH, Mai CY, Hou MM, Lv LJ, et al. Prehypertension During Normotensive Pregnancy and Postpartum Clustering of Cardiometabolic Risk Factors: A Prospective Cohort Study. Hypertension 2016; 68: 455-463.

84. He D, Wu S, Zhao H, Zheng Z, Zhang W. High normal blood pressure in early pregnancy also contribute to early onset preeclampsia and severe preeclampsia. Clin Exp Hypertens 2018; 40: 539-546.

85. Wikstrom AK, Gunnarsdottir J, Nelander M, Simic M, Stephansson O, Cnattingius S. Prehypertension in Pregnancy and Risks of Small for Gestational Age Infant and Stillbirth. Hypertension 2016; 67: 640-646.

86. Moinuddin A, Gupta R, Saxena Y. Autonomic function tests in prehypertensive young adult males of Uttarakhand Region. Indian J Physiol Pharmacol 2016; 60: 45-51. 